\title{
What Can Our Nose Tell Us About Possible Treatments for Alzheimer's Disease?
}

Can. J. Neurol. Sci. 2003; 30: 3

It has long been recognized that olfactory deficits are observed in patients with Alzheimer's Disease (AD) and Parkinson's disease. ${ }^{1}$ In fact, in the mid 1980s it was hypothesized that nasal inhalation of toxins might contribute to the etiology of some cases of $\mathrm{AD}^{2,3}$ Most remarkable were the studies that suggested that olfactory deficits occurred in the preclinical course of AD. ${ }^{4}$ However, the precise anatomical and neurodegenerative relationship between the olfactory system and cognitive centers of the AD brains had not been carefully analyzed.

In the current issue, Christen-Zaech and colleagues ${ }^{5}$ have asked a most critical question - to what extent do degenerative changes in the olfactory bulb $(\mathrm{OB})$ relate to those in the cerebral cortex in cases of AD? Four groups of postmortem brains were studied, those from a control group and three groups with increasing severity of AD. The findings are clear and compelling. The authors report that there is a significant correlation between the olfactory bulb and cerebral cortex as regards the frequency and severity of AD-type neurodegeneration. Most noteworthy is that degenerative changes in the $\mathrm{OB}$ are observed even in $\mathrm{AD}$ cases with discrete and moderate degeneration in the cortex.

The findings of Christen-Zaech and colleagues are both interesting and important. The importance of the findings is at several levels. First, the precise correlation between degenerative changes in the $\mathrm{OB}$ and cerebral cortex suggest that common mechanisms may operate in the origin and development of the pathological changes in these structures. Second, the degenerative changes in the OB suggest that the behavioural deficit observed in olfaction is likely due to the changes in central nervous sytem function. Taken together with the observations that such deficits occur prior to any apparent cognitive impairment, these findings point to the possibility that well-designed neuropsychological testing for olfactory memory and discrimination may provide accurate preclinical diagnoses of AD. As novel therapies emerge, it is reasonable to suggest that such diagnoses may allow for more aggressive and successful treatment of the nonfamilial form of AD.

The results of this study are most interesting when taken together with previous observations from the same laboratory. Miklossy et $\mathrm{al}^{6}$ reported that degenerative changes are also observed in the ependyma and choroid plexus in AD. And thus the plot thickens, for indeed there is a thread that binds the choroid plexus/ependyma region, the $\mathrm{OB}$ and cerebral cortex. The choroid plexus and ependyma are intimately associated with the adult forebrain germinal zone, where neural stem cells produce olfactory interneurons throughout the lifetime of all mammals, ${ }^{7}$ including primates. ${ }^{8}$ It has been reported that, in some circumstances, these olfactory interneurons may be redirected towards the cortex or striatum, in particular after cortical lesion or injury. ${ }^{9-11}$ Might a deficit in the regenerative capacity of the adult forebrain germinal zone contribute to the pathology of AD? In fact, studies show that there is a reduction in proliferation within the adult forebrain germinal zone in aged mice. ${ }^{12}$ In any case, given that the generation of new neurons is an exciting and novel therapeutic avenue for brain injury or disease, studies aimed at exploring these relationships further will be most insightful.

Samuel Weiss Calgary, $A B$

\section{REFERENCES}

1. Mesholam RI, Moberg PJ, Mahr RN, Doty RL. Olfaction in neurodegenerative disease: a meta-analysis of olfactory functioning in Alzheimer's and Parkinson's diseases. Arch Neurol 1998;55:84-90.

2. Roberts E. Alzheimer's disease may begin in the nose and may be caused by aluminosilicates. Neurobiol Aging 1986;7:561-567.

3. Perl DP, Good PF. Uptake of aluminium into central nervous system along nasal-olfactory pathways. Lancet 1987;1:1028.

4. Murphy C, Gilmore MM, Seery CS, Salmon DP, Lasker BR. Olfactory thresholds are associated with degree of dementia in Alzheimer's disease. Neurobiol Aging 1990;11:465-469.

5. Christen-Zaech S, Kraftsik R, Pillevuit O. Early Olfactory Involvement in Alzheimer's Disease. Can J Neurol Sci 2003; 30:20-25

6. Miklossy J, Kraftsik R, Pillevuit O, et al. Curly fiber and tangle-like inclusions in the ependyma and choroid plexus--a pathogenetic relationship with the cortical Alzheimer-type changes? J Neuropathol Exp Neurol 1998;57:1202-1212.

7. van der Kooy D, Weiss S. Why stem cells? Science 2000;287:14391441.

8. Kornack DR, Rakic P. The generation, migration, and differentiation of olfactory neurons in the adult primate brain. Proc Natl Acad Sci USA2001;98:4752-4757.

9. Arvidsson A, Collin T, Kirik D, Kokaia Z, Lindvall O. Neuronal replacement from endogenous precursors in the adult brain after stroke. Nat Med 2002;8:963-970.

10. Magavi SS, Leavitt BR, Macklis JD. Induction of neurogenesis in the neocortex of adult mice. Nature 2000;405:951-955.

11. Gould E, Reeves AJ, Graziano MS, Gross CG. Neurogenesis in the neocortex of adult primates. Science 1999;286:548-552.

12. Tropepe V, Craig CG, Morshead CM, van der Kooy D. Transforming growth factor-alpha null and senescent mice show decreased neural progenitor cell proliferation in the forebrain subependyma. J Neurosci 1997;17:7850-7859. 